\title{
Kids are Kids: Corona-Proofing Early Childhood Programs in the Republic of Korea
}

\author{
Carolyn Victoria Uy Ronquillo \\ Department of Early Childhood Education, College of Public Health and Welfare, Woosong University, Republic of Korea
}

\section{How to cite}

Ronquillo, C. V. U. (2021). Kids are Kids: Corona-Proofing Early Childhood Programs in the Republic of Korea. Asia Pacific Journal on Curriculum Studies, 4(1), 1-7. https://oi.org/10.53420/apjcs.2021.1

\begin{abstract}
As of January 26, 2021, around 18.8 percent of confirmed COVID-19 patients in the Republic of Korea were in their 50 's and only $3.75 \%$ were children below 10 years old. This figure may just be a drop in the bucket, yet the profound effects of this global pandemic on young children's development cannot be overlooked. COVID-19 has not yet been considered a "children's disease" because of very few confirmed cases and for those who have contracted it, the fatality rate has been very low. Relying on an aggressive trace-test-and-quarantine program, South Korea has so far weathered this crisis without major lockdowns. It has been hailed by various countries for "flattening the curve" in a short period of time. This paper investigates how the education sector in South Korea responded to the COVID-19 pandemic. It documents the educational experiences in making the Nuri Curriculum more relevant and effective as significant educational adjustments were put into action to deal with the new policies related to South Korea's COVID-19 response. A description of the innovative alternative practices in terms of the physical and temporal environments as well as curricular strategies implemented in Kindergarten schools and child care centers are elaborated in this paper. This is supplemented with feedback gathered from interviews with early childhood educators, which reveal both the difficulties and psychological rewards that they have experienced.
\end{abstract}

Keywords: South Korea, COVID-19 pandemic, early childhood programs, early childhood educators, early childhood curriculum

\section{Introduction}

The first coronavirus disease (COVID-19) case in South Korea was reported on January 20, 2020 during the winter break in most schools. By February 17th, there were about 10,000 cases which showed how the situation quickly worsened in just one month (Won Su, 2020).

The South Korean government through its Korea Disease Control and Prevention Agency (KDCPA) then issued new policies to address the COVID-19 pandemic. These broadly include: (a) eased distancing in daily life (or social pause); (b) shift to online classes after school opening was postponed three times; and (c) recommendation on work from home arrangement. Relying on an aggressive trace-test-and-quarantine program and mandatory use of facemasks, South Korea has so far weathered this pandemic without major lockdowns. In addition, Korea developed a three-tiered Infectious Disease Risk Alert for its citizens. Level 1 (referred to as "Attention") is where daily life is permitted as usual without special restrictions, including wearing of facemasks, but high levels of testing were initiated to effectively screen people of the virus. Level 2 ("Boundary") wherein there were enforced quarantine restrictions of infected people in isolation wards or at home. Extensive procedures for contact tracing were initiated, such as CCTV footage or ATM cards used in the area. The highest is Level 3 ("Severity") which required the entire country to be locked down. Korea's quick response was in line with lessons learned from how it managed the Middle East Respiratory Syndrome (MERS) outbreak in 2015. In a way, the difficulties they encountered with MERS became a blessing in disguise for preparing Korea's response to COVID-19.

By April 2020, various countries have commended South Korea for its efforts to control the outbreak, without declaring an economic lockdown or paralyzing their health system (USFDA, 2020). South Korea became a model for other nations to emulate in fighting COVID-19. This was attributed to an early response system as soon as the first case was detected, real-time and frequent dissemination of information to the public, tapping the private sector to help the government, and an organized national effort (rather than by provincial or city levels) in solving the pandemic. Korean citizens have been used to wearing facemasks due to the yellow dust and air pollution they have been experiencing through the years. Hence, it was not difficult to 
mandate the people to wear facemasks during the pandemic. On their own, they avoided going to crowded places, and preferred to do online than physical shopping. In addition, with the high-speed internet, widespread use of smartphones, and mobile apps, South Koreans received updates at once which they share with their family and peers. Furthermore, the government's timely approval of diagnostic tests, heightened border control and meticulous contact mapping were factors that contributed to its successful "flattening of the curve" of COVID-19 cases in a short period of time.

Before discussing the innovative changes that South Korea implemented in the education area, specifically in the early childhood sector, it is interesting to look into the number of coronavirus cases as of January 26, 2021. The table below shows that the age group of children below ten, comprised the smallest group, with only $3.75 \%(n=2,832)$ of the total cases $(\mathrm{N}=75,521)$.

Table 1

Age Distribution of COVID-19 Cases in South Korea as of January 26, 2021

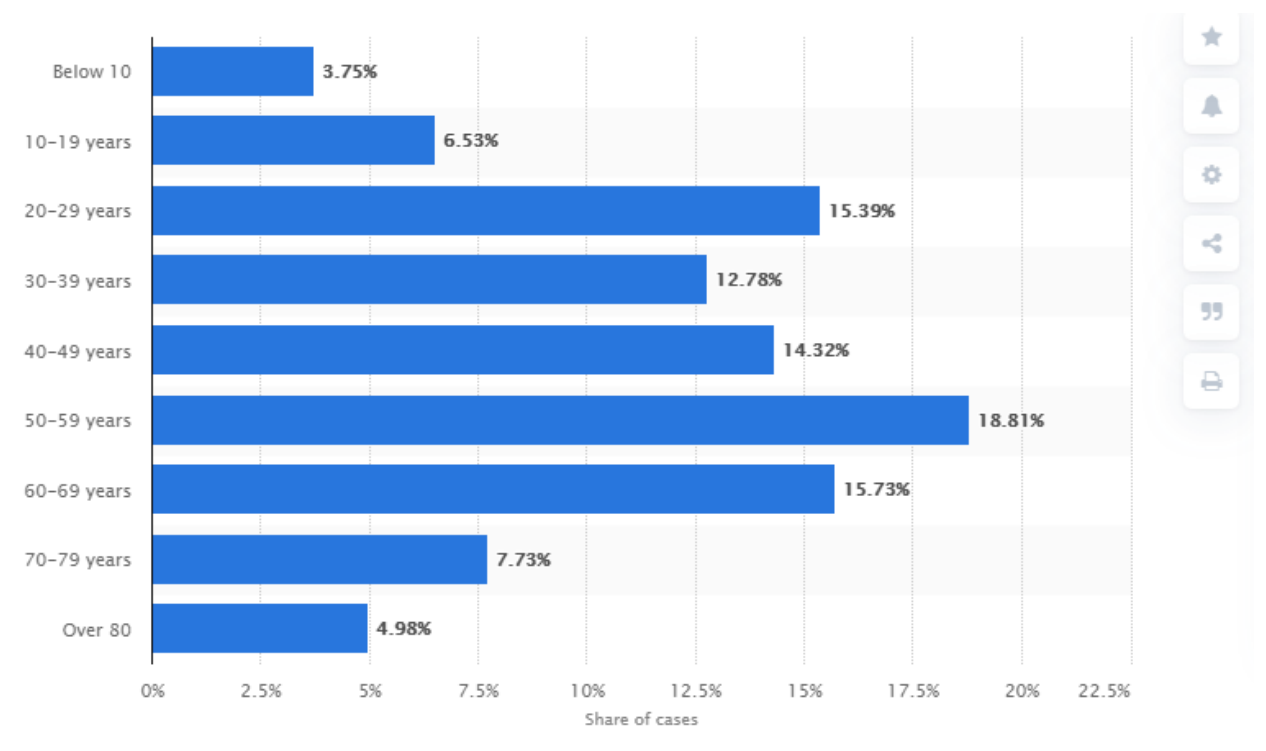

Source: https://www.statista.com/statistics/1102730/south-korea-coronavirus-cases-by-age/.

COVID-19 has not yet been considered a "children's disease" because there have been very few confirmed cases and for the very few who have contracted the COVID, the fatality rate has been very low. This figure may just be a drop in the bucket, yet when we consider all aspects of young children's development, the profound effects of this global pandemic are apparent. Dr. Eunhye Park, a faculty member of the Ehwa Woman's University and Director of its laboratory kindergarten school which is the oldest preschool in Korea, said that due to COVID-19, children have had to cope with physical distancing, quarantines, limited interaction with family and friends, and regulated outdoor play. These have caused critical changes in terms of the routines in Kindergarten schools and day care centers. In a webinar conducted by the Southeast Asia Ministers of Education Organization (SEAMEO) last June 2020, former President of Korea National University of Education, Dr. Lew Hee Chan, recognized that this pandemic has brought about considerable modifications in the education and care of children in early childhood centers. The other speakers who were likewise early childhood educators from Asia, shared the same sentiments that indeed the COVID-19 disease has been restricting the movements of children and this is detrimental to the over-all development of the children.

Significant education-related adjustments were put into action to deal with the new policies on the COVID-19 response. This paper investigates how the South Korean government countered the COVID-19 crisis and mitigated its impact on early childhood education services. The innovative alternative practices introduced in terms of the physical and temporal environments as well as curricular strategies implemented by early childhood educators are described based on interviews conducted by this author. Two mothers were also interviewed about their experiences in having their children attend childcare centers during the pandemic. Moreover, observations done at the University laboratory kindergarten school where the author is currently teaching are also included. For this paper, "early childhood programs" will pertain to kindergarten schools and child care centers, and "educators" will refer to early childhood teachers and child care workers. 


\section{The Nuri Curriculum of Korean Early Childhood Programs}

Prior to discussing the education-related modifications that have been implemented during the COVID-19 outbreak, it is necessary to provide a short background on the curriculum of early childhood programs in South Korea. In July 2012, aware of the nation's responsibility to strengthen early childhood education, the Korean government announced the creation of the Nuri Curriculum. This is a comprehensive program for children ages zero to five that aims to provide continuous child development and integration in early childhood education and care within the same national curriculum. The long-term plan of the South Korean government is for all children to lead happy lives and fulfill their hopes and dreams.

This national curriculum applies to both kindergarten schools and child care centers to ensure that all three to five-year old children are subject to the same national curriculum standards. The Ministry of Education oversees kindergarten schools while the Ministry of Health and Welfare is in charge of child care centers. This set-up guarantees equal educational opportunities for all young children with the government providing free educational expenses. Through innovations in the country's education culture, the Korean government is able to fulfill its mandate and responsibility on education delivery as a public good. The Nuri Curriculum encompasses five learning areas: physical exercise and health, communication, social relations, art and creative experiences, and nature exploration. In 2019, a revision was made to consider the various characteristics of individual young children; to encourage children's free play; and to respect teacher's autonomy in creating the curriculum.

As a signatory of the United Nations Convention of the Rights of the Child (UNCRC), South Korea also adheres to international laws and policies and continues to respect that children have the right to survive, the right to protection, the right to develop and the right to participate. The Nuri Curriculum is also Korea's response to the United Nations Sustainable Development Goals (SDG), specifically Goal 4.2 on equal access to high-quality early childhood education. Thus, the Nuri Curriculum has shifted to a play-based and child-centered direction as it considers the aspects of health, learning and psychosocial well-being (which is the SDG Performance Indicator 4.2.1).

In addition, the Nuri Curriculum is aligned with the OECD Education 2030 Learning Framework which aims for the well-being of individuals and society through competencies involving knowledge, skills, attitudes and values for the changing global scenario. The OECD Learning Compass 2030, likewise reiterates the child's nature to actively learn and explore through play, which is similarly the primary focus of the Nuri Curriculum (KICCE, 2019).

\section{Pandemic-Proofing Early Childhood Programs}

The COVID-19 crisis has brought about major challenges in the early childhood sector across the globe. With the pandemic, what strategies have been introduced into the South Korea education system in order to corona-proof its early childhood programs? Kids are kids. We are cognizant that young children are naturally inquisitive and physically active, and keeping them at home, even to do online classes are not viable alternatives. This section looks into how South Korea has addressed the needs of young children by examining the practices of kindergarten schools and child care centers at this time of crisis. This includes the innovations done in the physical classroom, the temporal environment which is the daily schedule of activities, the learning experiences and assessment in early childhood programs.

Unlike the primary and secondary schools, most early childhood centers were open and accommodated children during the pandemic. This was because early childhood services were abruptly placed at the forefront and these were identified as essential services. They provided child care support for frontline workers who were employed in hospitals and other critical industries such as transport and food supply services which needed to continue operations. The early childhood centers were also opened to children whose parents had to work from home but were not financially able to hire caretakers. Early childhood centers were not permitted to refuse children whose parents requested their services. The attendance rate for early childhood centers' emergency care services reached close to $80 \%$ in the first few months. The remaining children did online classes or watched educational programs, under the supervision of their parents or guardians. For early childhood education programs, the adult-child ratio required during the time of pandemic was one adult for every eight children (1:8). To support the early childhood facilities, the government shouldered the salaries of additional personnel who were hired to maintain the given ratio.

In order to support center-based educators and home-based parents, the government developed a program called, "My Kindergarten". For 40 minutes each day, this was streamed via public broadcasting channel. This program consisted of educational videos and learning packages. Television services and contents of the Korea Educational Broadcasting System (EBS) likewise provided varying learning strategies depending on the ages of the children in order to deliver developmentally-appropriate instruction. This was done to minimize the use of computers and smart devices because preschool children were believed to be too 
young to effectively engage in virtual communications and recommended not to be exposed to digital devices for long periods of time. In addition, the program included hygiene-related activities, hand washing and daily physical activities. It also gave tips to parents on how to play with open-ended materials that are accessible and easily found at home. Moreover, it attended to the psychologically well-being of the children. Each child care center embedded this resource into their program of activities.

Regarding the physical protocols inside the school environment, the following practices have been introduced. Upon entering the early childhood facility, the children's body temperature was checked by the teachers and/or day care workers. This was repeated after lunch and during dismissal. The educators also set up the learning space in a way that respects recommended physical distance, such as designating standing spots with colorful stickers or tape for the children to identify where to line up. Everyone in the early childhood facility was required to wear facemasks at all times. The educators demonstrated the proper hand washing technique as mandated by the World Health Organization (WHO). The children were instructed to wash their hands more often and for about two minutes at each time.

In terms of the physical environment, there were modifications in the classrooms. Children worked individually or in small groups to adhere to the physical distance rule. Large group undertakings such as music and movement activities have been limited. Even during outdoor play, children were reminded not to form groups with more than four children. In terms of temporal management, there was an increased time allotted to checking the body temperature of the children. For the educators, they had an additional responsibility of cleaning and disinfecting the learning materials and classrooms after classes.

Before the pandemic, during snack and lunch times, children sat beside anyone and anywhere without restrictions. The children spontaneously shared stories while eating. Children used glasses from the school kitchen and got water from the water dispenser machine. However, during the coronavirus outbreak, transparent dividers had to be installed on the tables to separate children from sitting beside each other. The children had to follow an alternate seating arrangement. Children were divided into groups, and were then scheduled to use the dining area, one group at a time. They had to avoid talking while eating to further avoid the spread of the virus. They had to bring their own water flasks and their own eating utensils and hand towels to dry their hands. Brushing of teeth after eating was no longer allowed.

In terms of feedback on the daily activities, the parents and guardians downloaded the Kids Note App. This contained the Announcements from the Government and/or the early childhood center; Updates on COVID-19 pandemic; Letters / Notices for Parents; Menu for the Day, among others. The teachers sent their feedback about the children's development and school activities to the parents via the Kids Note app. Photos and artworks were transmitted on a regular basis, usually twice a week. As an additional precaution, parents and guardians were restricted from spending too much time mingling with teachers or co-parents whenever they bring or pick up their children from the early childhood facility.

\section{Early Childhood Educators' Observations During the Pandemic}

This section describes the insights and observations of early childhood educators about their workload during the pandemic. These educators worked in kindergarten schools and/or child care centers. They were graduates of a four-year college degree on early childhood education and have at least three years of teaching experience. The educators said that at the beginning of the pandemic, they met with the administrators of the early childhood facility to brainstorm and develop plans to modify the learning activities, teaching methods and facilities. They adapted the curriculum in order to integrate measures for COVID-19 prevention and hygiene protocols. As a result, they now have to do more meticulous checking of the general health status of the children. They have an additional responsibility of taking the body temperature of the children upon arrival, at mid-day and prior to dismissal. Furthermore, it became mandatory for them to clean and disinfect the instructional materials, classroom furnishings, and learning equipment in every nook of the kindergarten school or child care center after classes. The main focus during the pandemic was to keep the virus from spreading. Notably, the educators did not complain since they knew that this was necessary to keep everyone safe. There is an existing district regulation which states that if a child in the center would test positive for COVID-19, all early childhood programs in the area would be required to close for two weeks. Thus, the teachers had to be extremely careful in adhering to social distancing by checking that the children avoid large group activities, minimize sharing of toys and maximize the space available for learning activities.

One educator shared that "I spend a lot of my time adjusting the curriculum." Truly, there have been many curricular challenges at this time. Whereas there were mostly whole class activities like storytelling before the pandemic, these have now been reduced. Teachers now plan more individualized activities. A silver lining is that since the Nuri Curriculum was recently revised to focus on more play and child-directed activities, the teachers took this as a chance to plan and implement the new curriculum in more comfortable settings. The pandemic provided them with more time to improve their activity plans and teaching strategies since 
there were smaller groups of children to work with as dictated by the COVID-19 policies. Moreover, the teachers expressed that they had to be vigilant at all times about COVID-related updates sent through their telephone app. If there were high cases reported, they knew that there was a possibility of class suspension. This meant that they would need to send the children home immediately upon instructions from the local authorities.
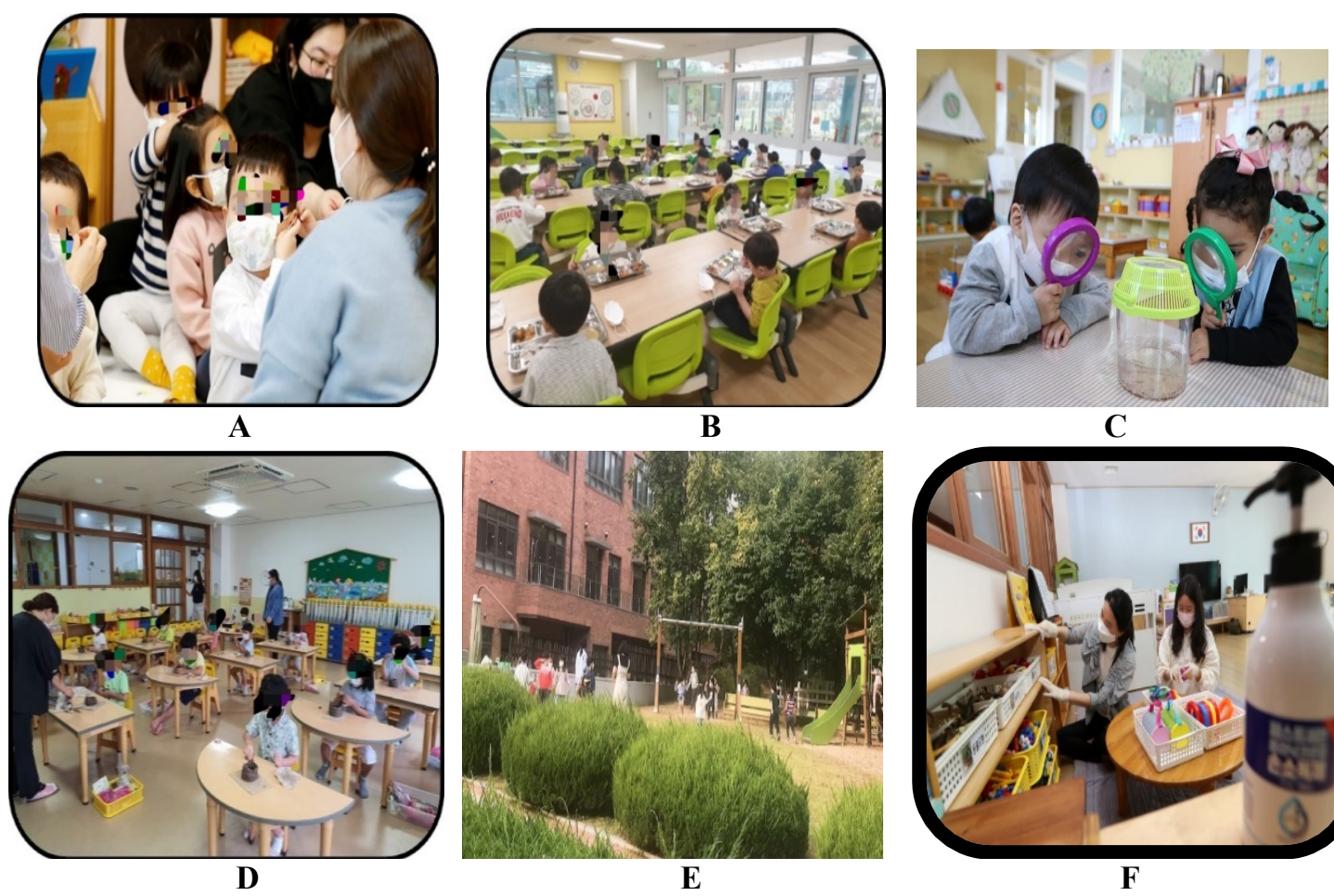

$\mathbf{E}$
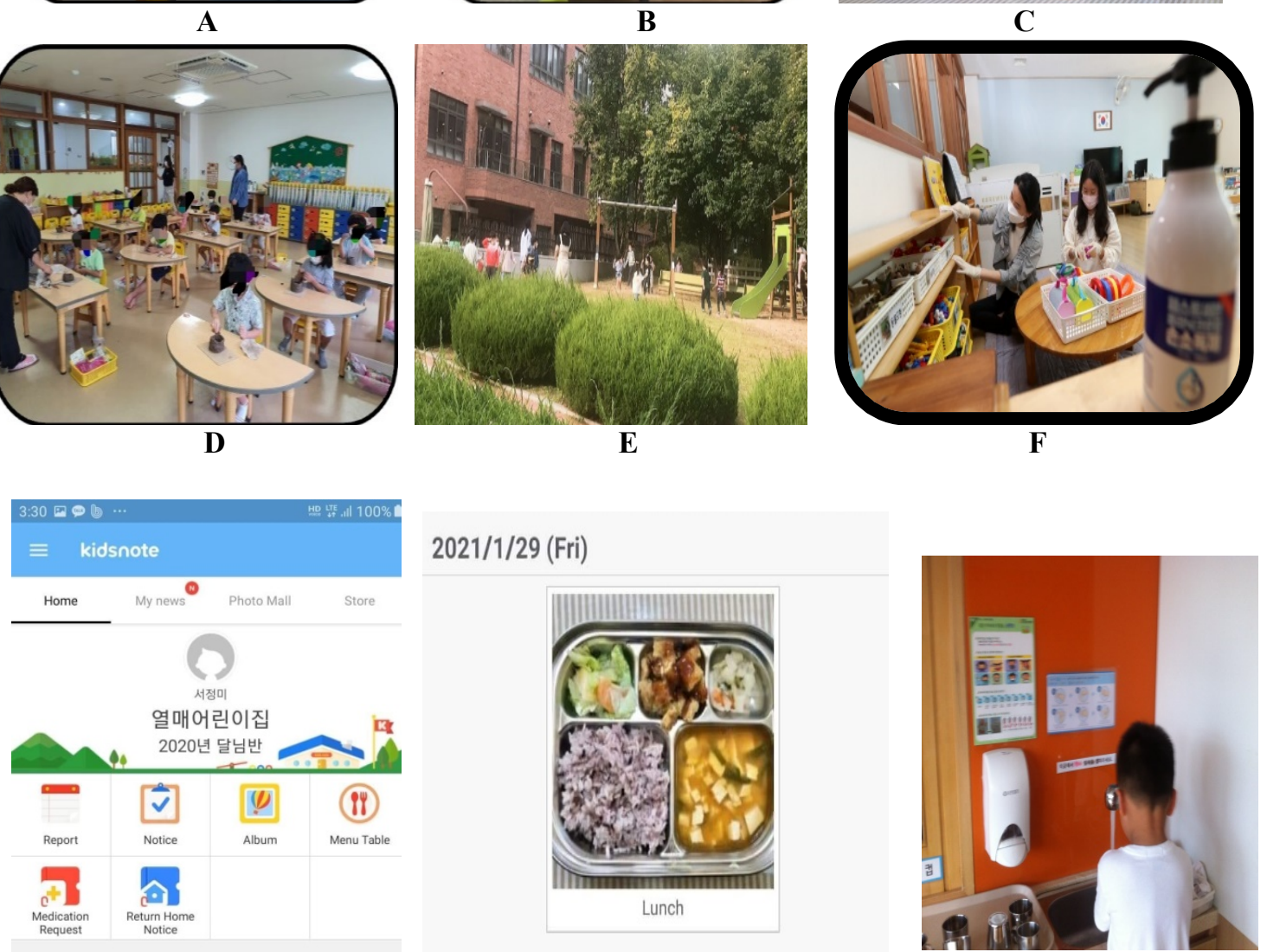

G

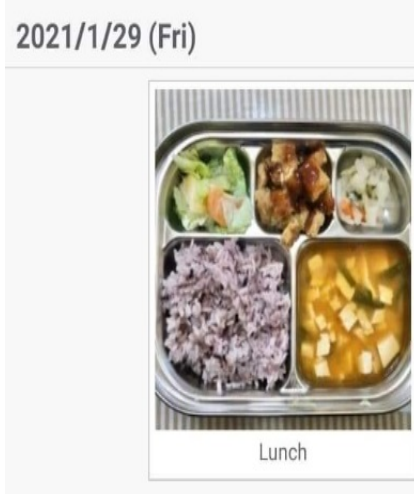

H

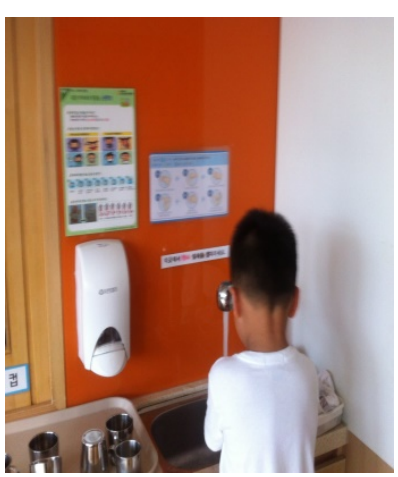

I

Figure 1. Examples of innovative changes in South Korean early childhood programs during the COVID-19 pandemic. From left to right: (A) Children wear their facemasks at all times. (B) During snack or lunch time, children follow a seating arrangement to observe physical distancing. Note the transparent dividers attached to the tables; $(C)$ Only two children can share a table in the different learning areas. (D) Children work and play at their individual desks. (E) Outdoor play is limited to groups of less than four children. $(F)$ Early childhood educators disinfect the instructional materials, furnishings and equipment in the early childhood facility. $(G)$ The Kids App for parents to monitor the important announcements and learning activities, among others. (H) The Kids App shows the menu for lunch for each day. (I) A boy does hand washing for about two minutes as taught by the teachers and mandated by the WHO. 
These were the general feelings expressed by the early childhood educators about their pandemic teaching experience. They felt anxiety and tension, since the children or they themselves might get infected with the corona virus. Most of them rode the public bus from their homes to their workplace, and this was a big risk for them. The educators vented their helplessness and sadness whenever the children expressed that they wanted to touch, hug or kiss their classmates and teachers. They felt tired since they had to devote more time disinfecting. They were stressed because they had to take more photos and videos for documentation and sharing in the Kids App. Nevertheless, they continued to feel grateful and proud. At this time of the COVID-19 pandemic, being recognized as heroes is an honor and a meaningful psychological reward for these educators.

\section{Ways Forward: Early Childhood Programs in the New Normal}

The curriculum is one of the factors that determine the success of any early childhood program. Aligning the needs of the children, parents' expectations and the educational philosophy of the school, are paramount in planning, implementing and evaluating curriculum implementation. Unfortunately, the COVID-19 pandemic has altered the scenario and consequently, the curriculum in early childhood programs in South Korea. The descriptions earlier discussed highlight three emerging issues from the impact of the COVID-19 crisis on the early childhood programs. First is that there have been more individualized and small group activities instead of whole class activities. At this age, young children's communication and social skills are developing rapidly. They are naturally affectionate, and show their love for others by touching, hugging, or even kissing. However, these are no longer allowed in their early childhood experience. It has taken a toll on the social development of children, who need more interaction and engagement with peers and adults at this young stage. Second, children need consistent assurances that despite the crisis, everything will still be fine in the end. Routines, or the regularity of activities, are consistently done for the children to trust their environment. The pandemic has drastically altered the classroom arrangement, the schedule of activities, and the way to do things, like frequent hand washing. Early childhood educators have to serve as models and guides in efficiently handling classroom management to provide consistency to the children. Preschool children require opportunities for social engagement, developmentally-appropriate learning and play. In the process, early childhood centers are expected to continue to offer safe and inclusive learning environments for all children. Lastly, the psychological and physical well-being of the children and more importantly of the early childhood educators have been at risk. The wholistic development of each child is of outmost importance. The sustained support from the school administrators, the community and the government have tremendously abetted the preschool teachers and the child care workers in their awareness of the critical role they play at this time of crisis.

The COVID-19 pandemic continues across many countries and South Korea has not been spared. It is a challenge for adults to explain distressing, global issues like the corona virus outbreak to young children in a way that helps them feel better, while at the same time present factual information that acknowledges the seriousness of the situation. This will be reassuring to children and help them face the ongoing changes.

During times of crisis, children need emotional support from their parents and educators to help them feel safe and secure. Since this pandemic may continue for sometime, these significant others must be prepared to talk with the children about this and encourage them to ask questions so they will learn how to protect themselves. The early childhood programs need to capitalize on teachable moments to help the children comprehend and appreciate why measures are being taken to keep them and others healthy. Play, physical activities, social interaction, and good mental health are essential for young children and these should be prioritized.

Early childhood program administrators, Kindergarten teachers, and child care workers must be acknowledged for re-creating the Nuri Curriculum to be more relevant and effective during the COVID-19 pandemic. In addition, the Korean government, especially those responsible for the welfare and education of children, should be lauded for addressing the needs and interests of their wards at this crucial time. Indeed, what they have introduced and implemented at the early childhood programs indicate that they are the trailblazer and henceforth, hailed as a model for other countries to follow.

\section{References}

Byun, Sooyeon, \& Slavin, Robert E. (2020). Educational responses to the COVID-19 outbreak in South Korea. Best Evidence in Chinese Education, 5(2), 665-680. https://doi.org/10.15354/bece.20.or030.

Kang, J., Jang, Y. Y., Kim, J., Han, S. H., Lee, K. R., Kim, M., \& Eom, J. S. (2020). South Korea's responses to stop the COVID19 pandemic. American Journal of Infection Control, 48(9), 1080-1086. https://doi.10.1016/j.ajic.2020.06.003 
Korea Institute of Child Care and Education. (2013). Policy Brief Issue 2. Nuri Curriculum: The first step toward the integration of the split systems of early childhood education and care in Korea.

https://kicce.re.kr/eng/board/view.do?menu_idx=26\&editMode=ADD\&board_idx=32593\&manage_idx=89\&old_menu_id $\mathrm{x}=0$ \&old_manage_idx $=0$ \&old_board_idx $=\overline{0} \&$ group_depth $=0 \& p a r e n t \_i d x=0 \&$ group_idx $=0 \&$ group_ord $=0 \& v i e w M o d e=N$ 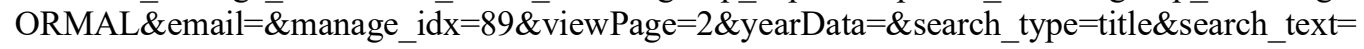

Korea Institute of Child Care and Education. (2019). Policy Brief Issue 14. Understanding the 2019 revised Nuri Curriculum. https://kicce.re.kr/eng/board/view.do?menu_idx=26\&editMode=ADD\&board_idx=32581\&manage_idx=89\&old_menu_id $\mathrm{x}=0$ \&old_manage_idx $=0$ \&old_board_idx $=\overline{0} \&$ group_depth $=0 \&$ parent_idx $=0$ \&group_idx $=0 \&$ group_ord $=0 \& v i e w M o d e=\bar{N}$ 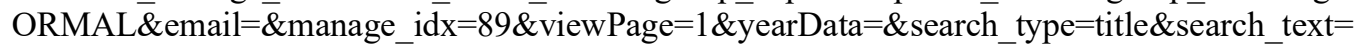

Park, E., Logan, H., Zhang, L., Kamigaichi, N., \& Kulapichitr, U. (2020). Responses to coronavirus pandemic in early childhood services across five countries in the Asia-Pacific region: OMEP Policy Forum. International Journal of Early Childhood, 52(3), 249-266. https://doi.org/10.1007/s13158-020-00278-0

Park, J., \& Chung, E. (2021). Learning from past pandemic governance: Early response and Public-Private Partnerships in testing of COVID-19 in South Korea. World Development, 137, 105198.

https://www.ncbi.nlm.nih.gov/pmc/articles/PMC7500944/\#!po=0.245098.

Southeast Asia Ministers of Education Organization. (2020, June 9). Embracing a New Normal in Early Childhood Education (ECCE) and Parenting. https://www.seameo.org/Main_programme/230

United Nations Children Fund, World Health Organization and the United Nations Educational, Scientific and Culture Organization. (2020). Global guidance on reopening early childhood education settings.

https://www.unicef.org/documents/guidance-on-reopening-early-childhood-education-settings

United States Food and Drug Administration. (2020). South Korea's response to COVID-19. Retrieved from https:/www.fda.gov/medical-devices/coronavirus-covid-19-and-medical-devices/south-koreas-response-covid-19

Won Su. (2020, January 26). Distribution of COVID-19 cases South Korea 2021, by age. https://www.statista.com/statistics/1102730/south-korea-coronavirus-cases-by-age/

World Health Organization. (2020, March 27). A timeline of South Korea's response to COVID-19. https://www.csis.org/analysis/timeline-south-koreas-response-covid-19

Yoon, D. (2020, September 9). South Korea's Coronavirus Lesson: School's Out for a While. http://www.arirang.co.kr/News/News_View.asp?nseq=271419.

You, J. (2020). Lessons from South Korea's Covid-19 policy response. American Review of Public Administration, 50, $801-808$. https://doi.org/10.1177/0275074020943708 